Revista de Ciencias Sociales - Número 71 (2017) - Páginas 35-65

Estudio crítico sobre el sentido y ámbito de aplicación del Recurso de Amparo Económico

\title{
ESTUDIO CRÍTICO SOBRE EL SENTIDO Y ÁMBITO DE APLICACIÓN DEL RECURSO DE AMPARO ECONÓMICO
}

\author{
CRITICAL STUDY ON THE SENSE AND SCOPE \\ OF THE APPLICATION OF ECONOMIC \\ PROTECTION ACTION
}

CAROLINA ARCIL CAMPOS*

\section{Resumen}

El ámbito de protección del Recurso de Amparo Económico (RAE) no es un tema pacífico ni en la doctrina ni en la jurisprudencia. En materia jurisprudencial, ha experimentado tres etapas marcadas, la última de ellas iniciada el año 2009, año en que la Corte Suprema adopta un criterio de aplicación restrictiva del recurso, limitándolo a la tutela del inciso segundo del artículo $19 \mathrm{~N}^{\circ} 21$ de la CPR. En los últimos años se han dictado aisladamente fallos en que la Corte vuelve a una interpretación amplia del recurso. El presente artículo revisa someramente la jurisprudencia y doctrina en la materia, y expone la opinión de su autora, fundada en la naturaleza jurídica del artículo $19 \mathrm{~N}^{\circ} 21$ de la Constitución y en la interpretación de las normas conforme a criterios hermenéuticos propios del ámbito constitucional.

Palabras clave

Recurso de amparo económico, libre iniciativa económica, estatuto del estado empresario, interpretación constitucional, Constitución Económica.

\footnotetext{
* Carolina Arcil Campos, Magíster en Derecho Constitucional, Universidad de Valparaíso, Valparaíso, Chile. carolaarcil@hotmail.com Artículo recibido el 16 de agosto de 2017 y aceptado el 19 de octubre de 2017.
}

Revista de Ciencias Sociales - Número 71 (2017) - Universidad de Valparáíso - ISSN 0716-7725-Valparáiso, Chile 


\begin{abstract}
The application of the economic protection action is not a pacific issue in doctrine nor in jurisprudence. In jurisprudential matter it has experienced three distinct stages, the last one initiated in the year 2009, when the Supreme Court adopts a restrictive application criteria of the economic protection action, limiting it to the tutelage of the second paragraph of the article $19 \mathrm{~N}^{\circ} 21$ of the Chilean Constitution. Nonetheless last years (since 2013) the Supreme Court has ruled more than once following a comprehensive criteria of both paragraphs of the above mentioned article. The present opinion piece reviews briefly the jurisprudence in this matter, and states the opinion of the author, founded on the legal nature of Article 19 Number 21 of the Chilean Constitution and on the interpretation of the legal regulations in accordance with hermeneutical criteria of the constitutional field.
\end{abstract}

\title{
Key words
}

Economic protection action, Free Economic Iniative, Statute of the Entrepeneurial State, Constitutional Interpretation, Economic Constitution.

\section{Introducción}

La ley $\mathrm{N}^{\circ}$ 18.971, de 1990, estableció el "recurso especial que indica", recurso ${ }^{1}$ que tanto la jurisprudencia como la doctrina han denominado "Recurso de Amparo Económico", probablemente por la remisión que hace el artículo único de la ley a las normas procedimentales del recurso de amparo que contemplaba el Código Procesal Penal.

De acuerdo al texto de la ley, el recurso tiene por objeto "denunciar las infracciones al artículo $19 \mathrm{~N}^{\circ} 21$ de la Constitución”, objeto que, como veremos, no se condice con los antecedentes propios de la historia fidedigna de su establecimiento. La principal polémica versa sobre el ámbito de protección del RAE, si el artículo único de la ley, aunque no hace distinción en su texto, debe interpretarse restrictivamente, esto es, sólo en relación al inciso segundo del numeral 21, o su ámbito de protección es amplio y alcanza a ambos incisos de la norma.

1. Le daré esa denominación siguiendo el texto expreso de la ley, aun cuando me parece que su naturaleza jurídica es propia de una acción jurisdiccional.

Facultad de Derecho y Ciencias Sociales - Universidad de Valparaíso - Chile 
El presente artículo tiene por objeto hacer una construcción dogmática de acuerdo a la normativa vigente, interpretada a la luz de los criterios hermenéuticos propios del análisis constitucional, que una vez analizado el contenido normativo del citado artículo $19 \mathrm{~N}^{\circ} 21$ y las acciones que lo protegen, permita sostener fundadamente que el recurso de amparo económico establecido en la ley $\mathrm{N}^{\circ} 18.971$ sólo es aplicable ante la transgresión de lo dispuesto en el inciso segundo del artículo 19 $\mathrm{N}^{\circ} 21$ de la CPR.

En pos de lo anterior, en primer término es indispensable analizar el contenido normativo de cada uno de los preceptos del artículo 19 $\mathrm{N}^{\circ} 21$ de la Constitución, de lo que me ocupo en el numeral 2.

En el numeral 3 expondré brevemente de los principales aspectos que caracterizan al RAE y al Recurso (Acción) de Protección, respectivamente. En el numeral 4 abordaré derechamente el controvertido tema del ámbito de aplicación del RAE, dando cuenta de las etapas jurisprudenciales. El numeral 5 tiene por objeto delimitar conceptualmente el ámbito de aplicación-protección de las acciones aludidas, interpretando los preceptos a la luz de la jurisprudencia tenida a la vista; el marco normativo de las normas que nos ocupan, y los criterios de interpretación constitucional, que no han sido considerados por nuestros tribunales al momento de resolver esta materia. Finalmente se cierra el artículo con algunas conclusiones.

\section{Contenido y alcance del artículo $19 \mathrm{n}^{\circ} 21$ de la Constitución Política de la República}

El artículo $19 \mathrm{~N}^{\circ} 21$ se ubica en el Capítulo III "De los derechos y deberes constitucionales" que consagra los derechos que la Constitución asegura a todas las personas ${ }^{2}$. Este precepto es nuevo en la historia

2. Artículo 19 numeral $21^{\circ}, \mathrm{CPR}$. "El derecho a desarrollar cualquiera actividad económica que no sea contraria a la moral, al orden público o a la seguridad nacional, respetando las normas legales que la regulen. El Estado y sus organismos podrán desarrollar actividades empresariales o participar en ellas sólo si una ley de quórum calificado los autoriza. En tal caso, esas actividades estarán sometidas a la legislación común aplicable a los particulares, sin perjuicio de las excepciones que por motivos justificados establezca la ley, la que deberá ser, asimismo, de quórum calificado".

Revista de Ciencias Sociales - Número 71 (2017) - Universidad de Valparaíso - ISSN 0716-7725-Valparaíso, Chile 
constitucional chilena, completa los derechos establecidos a favor de las personas y en conjunto con los derechos y garantías establecidos en los numerales $\mathrm{N}^{\mathrm{o}_{\mathrm{s}}} 16,20,22$ y 24, tienden a fortalecer la libertad económica. En esta materia, la Constitución del año 1980 se aleja del escenario que surgió al amparo de la Constitución de $1925^{3}$. A partir de 1973 se experimentó un giro, incorporando el principio de subsidiariedad y poniendo el acento en la libertad económica de los particulares. Este tema fue abordado derechamente en la Comisión de Estudios de la Nueva Constitución ${ }^{4}$.

La Constitución de 1980 sin duda optó por una primacía de la persona por sobre el Estado 5 . Disposiciones como el artículo $19 \mathrm{~N}^{\circ} 21$, norma que la mayoría de la doctrina considera como fundante del "orden público económico", son un reflejo de lo anterior. Desde mi perspectiva, el citado artículo y demás normas que tradicionalmente se enuncian en esta materia (principalmente los numerales 21 al 25 del artículo 19 de la Constitución), más que un "orden público económico", entendido como "el conjunto de principios y normas jurídicas que organizan la economía de un país y facultan a la autoridad para regularla”, consagró un orden jurídico económico, que no centra su contenido en lo limitante de la autonomía de la voluntad en el derecho privado que evoca el "orden público", sino que es en principio axiológicamente neutro ${ }^{7}$; normas que se adaptan al contexto político, social, económico al que deben aplicarse y cuyo contenido no es estático sino

3. ARÓSTICA, Iván: “Crónica sobre la expansión del Estado Empresario y el retraimiento de la iniciativa privada”. En: Ius Publicum, Universidad Santo Tomás, Escuela de Derecho, vol. 2, N 2, mar. 1999. p. 141.

4. BERTELSEN, Raúl: "El Estado Empresario en la Constitución de 1980". En: Revista Chilena de Derecho, vol. 14, 1987. Pp. 118 a 120.

5. ARÓSTICA, Iván, ob. cit.

6. AVILÉS, Víctor: “Orden Público Económico: Noción Crítica”. En: Revista de Derecho Público, vol. 63, pp. 329-338. P. 330, cita al concepto contenido en el fallo de la Corte de Apelaciones de Santiago, de 15 de junio de 1992.

7. Ídem.

Facultad de Derecho y Ciencias Sociales - Universidad de Valparaíso - Chile 
que se va construyendo por la doctrina y la jurisprudencia, y se interpretan a la luz de los principios consagrados en las Bases de la Institucionalidad. El contenido de estas normas que forman parte de lo que Zúñiga ${ }^{8}$ denomina "Constitución Económica”, es evolutivo.

Consideremos con más detención cada uno de los incisos de este numeral 21.

El inciso 1 del numeral 21 consagra el derecho subjetivo público a desarrollar actividades económicas. El ejercicio de este derecho debe efectuarse conforme a las normas legales que lo regulen, disposiciones que no pueden afectar la esencia del derecho. En cuanto a los límites a su ejercicio, el Constituyente señala tres: moral, orden público y seguridad nacional. Se consagra el derecho, y como contrapartida existe la obligación correlativa de no hacer, no perturbar ni menoscabar ese derecho, obligación que recae tanto en el Estado como en cualquier persona. Desde una perspectiva netamente jurídica, este inciso no es más que una consagración de la autonomía privada, autonomía de todas las personas para que desarrollen actividades económicas ${ }^{9}$.

Por su parte, el inciso segundo consagra el Estado Empresario. La doctrina $\mathrm{a}^{10}$ ha afirmado que este inciso plasma en materia económica, el principio de subsidiariedad, principio que resguarda la libertad consustancial del ser humano en nuestro ordenamiento constitucional, pues limita la irrupción del Estado en la vida social en beneficio de la autonomía de la voluntad que ejercen los individuos, las familias y los grupos intermedios. Considero que esta afirmación admite algunas consideraciones críticas. Este inciso segundo del artículo $19 \mathrm{~N}^{\circ} 21$ ha suscitado numerosas dificultades en su interpretación y aplicación

8. ZÚNIGA, Francisco: "Constitución económica y Estado empresario". En: Revista de Derecho Público, N 63, Tomo I, año 2001. Pp. 339 y sgtes.

9. GONZÁLEZ GRANDJEAN, Denis: La libertad económica y su Protección Jurídica en la Constitución Chilena: un análisis a través de la jurisprudencia. Memoria para optar al Grado de Licenciado en Ciencias Jurídicas y Sociales, Universidad de Chile, Santiago, 2001.

10. EVANS, Enrique; FERMANDOIS, Arturo; CEA, José Luis, entre otros.

Revista de Ciencias Sociales - Número 71 (2017) - Universidad de Valparáíso - ISSN 0716-7725-Valparaíso, Chile 
práctica, en la determinación del rol del Estado en cuanto a empresario en nuestro país.

Identifico dos doctrinas opuestas en relación al contenido normativo de esta disposición, y subrayo que la respuesta respecto del contenido normativo tiene especial trascendencia, pues de ella dependerá, en primer término, los aspectos que deberá considerar el Congreso Nacional, al aprobar una norma de quórum calificado que autorice la actividad empresarial del Estado. En segundo término, determinará la jurisprudencia de los Tribunales de Justicia, principalmente al conocer del recurso de amparo económico que protege la indicada norma. También podría determinar, eventualmente, el fallo de una acción de inaplicabilidad por inconstitucionalidad, planteada ante el Tribunal Constitucional, de una ley de quórum calificado que autorice la injerencia del Estado o de sus organismos en un ámbito de la actividad empresarial, y aún más, de acuerdo a la normativa constitucional vigente, se podría llegar a la derogación de una ley a través de la acción de inconstitucionalidad. Las dos principales posiciones doctrinarias en esta materia son.

A. Actividad empresarial del Estado: sólo en subsidio de la actividad de los particulares. La doctrina ${ }^{11}$ que tiene el carácter de mayoritaria, estima que el principio de subsidiariedad, si bien no está expresamente consagrado, es transversal en nuestra Constitución, nace en el artículo $1^{\circ}$, incisos 3 y 4 , y se plasma en múltiples otras normas, como es el caso del numeral $21^{\circ}$, del artículo 19 , que nos ocupa. Afirman que la Constitución es reticente al Estado empresario, el que para tener alguna forma de intervención en el área empresarial, debe cumplir con los requisitos del ya citado numeral, a lo que se adiciona el requisito no escrito de que dicha actividad empresarial no esté siendo desarrollada por particulares o bien lo estén efectuando de forma insatisfactoria. Esta doctrina se funda principalmente en la historia fidedigna del establecimiento de la norma ${ }^{12}$.

11. CEA, José Luis; BERTELSEN, Raúl; FERMANDOIS, Arturo, entre otros.

12. Interpretación originalista que está siendo descartada por la hermenéutica constitucional moderna y sólo expongo con fines ilustrativos de esta doctrina.

Facultad de Derecho y Ciencias Sociales - Universidad de Valparaíso - Chile 
B. La igualdad como principio inspirador del Estado Empresario. Me refiero aquí a los autores ${ }^{13}$ para quienes no es efectivo que el carácter empresarial del Estado sea sólo excepcional y en subsidio de la actividad de los particulares, sino que nuestra Constitución, aceptando la actividad empresarial del Estado, ha querido resguardar a los particulares, en concordancia con la libertad económica consagrada en el inciso primero, en cuanto a que la actividad estatal no será castradora de la actividad privada ni competirá en términos desleales frente a la misma. En miras de lo anterior, estableció una serie de requisitos de carácter formal, para autorizar la puesta en marcha del Estado Empresario, además de garantías consagradas en otros numerales. La doctrina a la que hago referencia en este epígrafe, tiene como principal fundamento el tenor del inciso segundo del numeral 21, disposición en que no hay referencia alguna a la inactividad o actividad deficiente de los particulares para autorizar la actividad empresarial del Estado o de sus organismos; si la intención hubiera sido otra, se habría condicionado la autorización a la concurrencia de otros requisitos referidos a ella.

Lo que se busca garantizar, armonizando ambos incisos de la norma, es que esta libre iniciativa particular en materia económica no se vea menoscabada por la acción del Estado. Al respecto, lo que se quiere regular no es ya la actividad del Estado, sino asegurar que el desarrollo legítimo de actividades empresariales por parte de aquél, se haga en situación de igualdad respecto de los particulares, asegurándoles a éstos el derecho que se consagra en el inciso $1^{\circ}$, lo que reafirma la tesis que el principio que rige dicho inciso $2^{\circ}$ es el de igualdad y no el de subsidiariedad. Sería el principio de igualdad, además del de libertad, el que inspira esta norma. Igualdad tanto entre los particulares para el desarrollo de cualquier actividad económica, con los límites de la moral, el orden público y la seguridad nacional; igualdad entre los diversos organismos del Estado para desarrollar actividades empresariales o participar en ellas, con la exigencia que una ley de quórum calificado los autorice y, finalmente, igualdad entre los particulares y el Estado y sus organismos, cuando adquieren, con los requisitos legales, el carácter

13. RUIZ-TAGLE, Pablo: "Principios Constitucionales del Estado Empresario". En: Revista de Derecho Público, vol. 62, 2000. Pp. 48-65.

Revista de Ciencias Sociales - Número 71 (2017) - Universidad de Valparáíso - ISSN 0716-7725-Valparaíso, Chile 
de agentes económicos, al ser la legislación común aplicable a los particulares la que rige en este último caso.

\section{Contenido normativo de las disposiciones precedentes}

Entre las disposiciones de una Constitución podemos distinguir al menos: a) las que establecen las competencias y procedimientos de los órganos del Estado; b) las que reconocen y garantizan a los individuos los "derechos fundamentales"; c) las que expresan valores y principios que informan la propia Constitución y el resto del ordenamiento jurídico el cual ella encabeza ${ }^{14}$.

En mi parecer, la disposición contenida en el inciso primero del numeral 21, del artículo 19, se encuadra dentro de aquellas que reconocen y garantizan a los individuos derechos fundamentales, un derecho subjetivo de carácter económico ${ }^{15}$. En el inciso primero del numeral 21, del artículo 19 de la Constitución, sin duda nos encontramos con una facultad, un poder de actuar del individuo, consagración de su autonomía, con los límites que la propia Constitución establece. Y con una obligación genérica de los otros sujetos, sea que se trate de entes privados o públicos, de abstenerse de ejecutar acciones que coarten esa libertad para desarrollar actividades económicas.

Por su parte, el inciso segundo, del numeral 21, del artículo 19 de nuestra Constitución corresponde más bien a aquellas disposiciones señaladas en la letra a), una norma que establece las competencias y procedimientos de los órganos del Estado, cuando realizan actividades empresariales. Se trata de una norma que, no obstante su ubicación en el artículo 19, carece en sí misma de contenido sustantivo (el que ha sido dado por la doctrina), simplemente establece requisitos para el actuar del Estado empresario. Será la jurisprudencia la que, interpretando la Constitución, dotará a esta disposición de contenido, a la luz del principio de subsidiariedad, o de alguno de los otros principios que consagran las Bases de nuestra institucionalidad.

14. SQUELLA, Agustín: Introducción al Derecho. Segunda Edición actualizada y ampliada, Editorial Jurídica de Chile, Santiago, 2011.

15. Ídem.

\footnotetext{
Facultad de Derecho y Ciencias Sociales - Universidad de Valparaíso - Chile
} 
Establecer el contenido normativo de los incisos del numeral 21, artículo 19 de la Constitución es relevante pues ello determina el régimen de garantías y recursos aplicables a la protección de ambas normas.

\section{Acciones relacionadas con el artículo $19 \mathrm{n}^{\circ} 21$ de la Constitución Política de la República}

Este derecho fundamental se encuentra doblemente resguardado: por el recurso (acción) de protección y por el recurso (acción) de amparo económico ${ }^{16}$.

\subsection{Protección Constitucional. Recurso de Protección}

El artículo 20 de nuestra Constitución consagra el denominado "recurso de protección", aun cuando existe consenso que su naturaleza jurídica es más propia de una acción constitucional. Esta acción, que aparece por primera vez en nuestro ordenamiento en el Acta Constitucional $\mathrm{N}^{\circ} 3$, ha sido ampliamente estudiada por tanto no me detendré en este punto.

Sabemos que el recurso o acción de protección ampara ciertos derechos o garantías contenidos en determinados numerales del artículo 19 de la Constitución Política de la República. Como señala Gómez "la clave de la protección es la tutela de un derecho fundamental lesionado en una dimensión subjetiva de éste, vale decir, sólo si la posición del individuo agraviado por la acción u omisión se encuentra amparada por un derecho fundamental ${ }^{\prime 17}$. Nuestro interés en esta acción se centra en la forma como protege el artículo $19 \mathrm{~N}^{\circ} 21$.

16. NAVARRO, Enrique: “La libertad económica y su protección”. En: Revista del Abogado, $\mathrm{N}^{\circ}$ 24, abril 2002. Pp. 28-30.

17. GÓMEZ, Gastón: Derechos fundamentales y recurso de protección. Ediciones Universidad Diego Portales, Facultad de Derecho, Santiago, 2005. P. 19.

Revista de Ciencias Sociales - Número 71 (2017) - Universidad de Valparáíso - ISSN 0716-7725-Valparaíso, Chile 


\subsection{Protección Legal. Recurso de Amparo Económico}

La ley $\mathrm{N}^{\circ} 18.971$, orgánica constitucional, que "Establece el recurso especial que indica", consta de un artículo único, que consagró el comúnmente denominado "Recurso de Amparo Económico"18. Como rasgos principales de la acción destacamos:

- No obstante el epígrafe de la ley que lo establece, se trata de una verdadera acción, por la que se solicita el ejercicio de la actividad jurisdiccional;

- Es una acción popular; su plazo de interposición de 6 meses, desde que se hubiere cometido la infracción, y el Tribunal competente de acuerdo a la ley es la "Corte de Apelaciones respectiva".

- En cuanto a la "causa" de esta acción, se ha producido una diferencia de interpretación que más adelante nos ocupará, pero el texto de la ley señala que su objeto es denunciar las infracciones al artículo 19 N $^{\circ} 21$ de la Constitución Política de la República.

- Está sujeta a una tramitación muy simple, según la ley que lo establece "se intentará sin más formalidad ni procedimiento que el establecido para el Recurso de Amparo".

- El recurso puede ser apelado, dentro de quinto día de notificada la sentencia. Si no es apelado, la Corte Suprema lo conoce en trámite de consulta.

18. "Artículo único.- Cualquier persona podrá denunciar las infracciones al artículo 19, número 21, de la Constitución Política de la República de Chile.

El actor no necesitará tener interés actual en los hechos denunciados.

La acción podrá intentarse dentro de seis meses contados desde que se hubiere producido la infracción, sin más formalidad ni procedimiento que el establecido para el recurso de amparo, ante la Corte de Apelaciones respectiva, la que conocerá de ella en primera instancia. Deducida la acción, el tribunal deberá investigar la infracción denunciada $y$ dar curso progresivo a los autos hasta el fallo respectivo.

Contra la sentencia definitiva, procederá el recurso de apelación, que deberá interponerse en el plazo de cinco días, para ante la Corte Suprema y que, en caso de no serlo, deberá ser consultada. Este Tribunal conocerá del negocio en una de sus Salas.

Si la sentencia estableciere fundadamente que la denuncia carece de toda base, el actor será responsable de los perjuicios que hubiere causado".

Facultad de Derecho y Ciencias Sociales - Universidad de Valparaíso - Chile 
La finalidad de este recurso ha sido objeto de una importante revisión por parte de la Corte Suprema. El principal punto de discusión es si, junto con el inciso $2^{\circ}$ del artículo $19 \mathrm{~N}^{\circ} 21$, protege también el $1^{\circ}$.

\section{4. Ámbito de aplicación del recurso de amparo económico (RAE)}

Etapas que ha presentado la jurisprudencia de la Corte Suprema:

Desde el año 1990, en que se dictó la ley $\mathrm{N}^{\circ}$ 18.971, que creó el recurso de amparo económico, hasta ahora, la Corte Suprema ha sostenido distintas posiciones respecto del ámbito de aplicación del RAE.

Distinguimos tres etapas bien delimitadas, y posteriormente, en los últimos años, una jurisprudencia más bien oscilante:

\subsection{El RAE está establecido para amparar solo el inciso 2, del artículo 19, $N^{\circ} 21$ de la $C P R$}

Es la jurisprudencia que primó en la primera etapa de aplicación de esta acción. La Sala Constitucional de la Corte Suprema interpretó que esta acción sólo estaba destinada a tutelar el cumplimiento de las exigencias constitucionales para que el Estado pueda desarrollar actividades económicas. Nogueira ${ }^{19}$ afirma que esta etapa tuvo una brevísima duración, entre 1990 y 1992. Hernández Emparanza ${ }^{20}$ le da una extensión mayor, entre 1990 y 1995.

En esta primera etapa el bien jurídico tutelado es el orden público económico, frente a los excesos del Estado empresario, es decir, el RAE se circunscribe a resguardar el inciso $2^{\circ}$ del artículo $19 \mathrm{~N}^{\circ} 21$ de la $\mathrm{CPE}^{21}$.

19. NOGUEIRA, Humberto: "Análisis Crítico sobre la línea jurisprudencial de la Sala Constitucional de la Excma. Corte Suprema de Justicia sobre el Recurso de Amparo Económico”. En: Ius et Praxis, vol. 16, núm. 2, 2010. P. 415.

20. HERNÁNDEZ, Domingo: "El recurso de Amparo Económico: una tendencia jurisprudencial peligrosamente reduccionista”. En: Estudios Constitucionales, año 8, $\mathrm{N}^{\circ}$ 1, 2010. P. 445.

21. Ídem.

Revista de Ciencias Sociales - Número 71 (2017) - Universidad de Valparáíso - ISSN 0716-7725-Valparáiso, Chile 
Entre las resoluciones que sostienen esta jurisprudencia, destacamos RAE CA Santiago, Cargill Incorporated Ltda. con Ministro de Obras Públicas, Rol 1210-2002, CS, Rol 1694-2002, 20/5/2002. Se concluye que el RAE tiene como finalidad la protección del orden público, entendiendo que se reduce a denunciar las transgresiones al inciso segundo del numeral 21, artículo 19 de la Constitución ${ }^{22}$.

En esta etapa jurisprudencial, Hernández señala que el recurso sólo habría sido procedente para amparar a las personas frente a casos en los que el Estado desarrolla actividades económicas sin respetar las reglas constitucionales y legales que le permitirían, de modo excepcional, hacerlo ${ }^{23}$.

En este período también encontramos fallos que acogen el RAE, precisamente pues la denuncia se funda en el actuar del Estado o sus organismos, sin cumplir con los requisitos del referido inciso segundo, como en "Asociación Gremial de Impresores de Chile con Ejército de Chile". La Corte de Apelaciones, en su considerando $12^{\circ}$, lo expresa en los siguientes términos: "12 recurso planteado aquí tiene fundamento es preciso, en primer término, determinar si el Instituto Geográfico Militar está autorizado por ley de quórum calificado para desarrollar actividades empresariales de impresión gráfica..."24.

El recurso fue acogido, declarando la Corte que el Instituto Geográfico Militar debe abstenerse de realizar trabajos de impresión gráfica a terceros, que no pertenezcan al área propia de su especialidad, determinada por las leyes orgánicas que lo regulan.

\subsection{El RAE ampara ambos incisos del artículo $19 N^{\circ} 21$ de la CPR}

El giro jurisprudencial, según Nogueira ${ }^{25}$, tuvo lugar en $1992^{26}$, con el fallo "Empresa Hidroeléctrica Pullinque S.A con Empresa

\footnotetext{
22. Ídem.

23. Ídem.

24. CA Santiago, Rol 2.396-91, de 5 de diciembre de 1991.

25. NOGUEIRA, Humberto, ob. cit.

26. El año 1992 falló el recurso la Corte de Apelaciones, pero es en 1995, con el fallo de la Corte Suprema, cuando se observa el giro jurisprudencial.
}

Facultad de Derecho y Ciencias Sociales - Universidad de Valparaíso - Chile 
Nacional de Electricidad Endesa SA". Este fallo sentó las bases de esta nueva jurisprudencia, resolviendo la Corte Suprema, conociendo en segunda instancia el recurso: "Que la ley $N^{\circ} 18.971$ estableció el recurso especial de amparo, para denunciar las infracciones al artículo 19, número 21, de la Constitución Política de la República de Chile, sin hacer distinción alguna entre las diversas situaciones planteadas en ambos incisos del señalado número 21;

Que, frente a lo expresado en el considerando anterior, las argumentaciones vertidas por la recurrida para concluir que el amparo económico sólo es procedente cuando se ha producido una infracción al inciso segundo del artículo 19 número 21 de la Carta Fundamental, no llevan al convencimiento de esta Corte en cuanto que así deba resolverlo, variando por lo demás con ello la jurisprudencia establecida por esta Sala especializada, cuando resolvió el recurso de amparo económico $N^{o} 24513$, el 28 de marzo último ${ }^{27}$;

En esta línea jurisprudencial, la Corte Suprema ha señalado: "La acción de amparo fue creada con el objeto de cautelar la garantía constitucional de la libertad económica que consagra el artículo 19 de la Constitución Política en ambos incisos de su número 21....Del tenor literal claramente manifestado por el texto de la Ley $N^{\circ} 18.971$, aparece que el recurso ampara la garantía constitucional estableciendo acción popular para denunciar todas las infracciones a dicha norma constitucional, ya que no hace distinciones entre sus dos incisos"28.

A mayor abundamiento, la Corte Suprema, revocando una sentencia de la Corte de Apelaciones, ha sostenido: “ $\left.4^{\circ}\right)$... Tratándose de una norma de tenor tan claro, no se divisa de qué manera podría restringirse la denuncia y correspondiente indagación tan sólo a una de las dos garantías que se protegen en el indicado precepto constitucional. En efecto, no hay ninguna circunstancia que permita una interpretación diferente, en orden a que ella estaría limitada únicamente al inciso segundo de la norma de la Carta Fundamental, y cualquier otro entendimiento carece de asidero

27. RAE, CS, Rol No 33502, de 10 de enero de 1996.

28. RAE, CS, "Comercial Agropecuaria Menichetti con Banco del Estado", Rol 3.899-94, 26/1/95.

Revista de Ciencias Sociales - Número 71 (2017) - Universidad de Valparáíso - ISSN 0716-7725-Valparaíso, Chile 
jurídico y contraría el claro sentido de la misma, que se desprende de su tenor literal ya reproducido" 29 .

La lectura de los fallos anteriores me lleva a concluir que, más que un análisis profundo respecto de la naturaleza jurídica y ámbito de aplicación de la Acción de Amparo Económico, lo que primó en estas sentencias fue la aplicación del conocido aforismo jurídico "donde la ley no distingue, no cabe al intérprete distinguir". Considero que en materia constitucional, el literalismo no puede ser la tónica interpretativa.

\subsection{El RAE está establecido para amparar sólo el inciso $2^{\circ}$ del artículo $19 N^{\circ} 21$ de la CPR}

En marzo de 2009, la jurisprudencia experimentó un nuevo cambio en esta materia. En la causa "Sergio Luis González Illanes con I. Municipalidad de Santiago"30, la Corte Suprema reinterpretó el artículo único de la ley $\mathrm{N}^{\circ} 18.971$, modificando la línea jurisprudencial sostenida durante diecisiete años.

Sin perjuicio de reproducir literalmente ciertas consideraciones del fallo, anoto aspectos relevantes:

- La Corte se propone expresamente reexaminar el sentido y alcance del RAE. La Corte se hace cargo de la oscilante jurisprudencia y hace un análisis del tema bastante más profundo de los que observamos en la etapa anterior.

- El fallo afirma que si bien el tenor literal de la norma es claro, no ocurre lo mismo con su sentido, que resulta ambiguo y que ha dado pábulo a la divergencia de opiniones suscitadas sobre el punto. Con ello la Corte "autoriza" a recurrir a otros métodos de interpretación mas allá del gramatical, en pos de una conclusión correcta en esta materia.

29. RAE CA Santiago, Valparaíso Sporting Club S.A con Wagner Brizzi María Eugenia, Subsecr. Hacienda, Rol 3572-2003, 5/6/2003, CS, Rol 3496-2003.

30. CS, Rol 501-2009.

Facultad de Derecho y Ciencias Sociales - Universidad de Valparaíso - Chile 
- El fallo hace referencia a otras reglas de hermenéutica civil, en primer término, al elemento histórico, recurrir a la historia fidedigna del establecimiento de la ley, particularmente al proyecto de ley rotulado "Regula la Actividad y Participación Productiva del Estado y sus Organismos", en el que "....se enunciaban como postulados esenciales del mismo los que propiciaban la iniciativa particular en la actividad económica y la excepcionalidad de la intervención en ella por parte del Estado empresario, consignándose en semejante contexto tres clases de normas unas, de carácter general, aplicables a toda legislación relativa a la actividad empresarial del Estado o en que a éste le quepa participación; otras, en que se fija el ámbito dentro del cual el Estado desarrollará actividades de ese tipo; y una, en particular, donde se establece un recurso jurisdiccional para hacer efectiva la garantía constitucional de la libertad económica.."31.

A partir de lo anterior, la Corte infiere que “...el recurso jurisdiccional a que ella alude se propende a amparar la garantía constitucional de la libertad económica frente al Estado empresario, cuando éste, transgrediendo un principio de la esencia del Orden Público Económico Nacional, como lo es el de la subsidiariedad, interviene en el campo económico no acatando las limitaciones contempladas en el antes citado artículo $19 N^{\circ} 21$ inciso $2^{\circ}$ de la Carta Fundamental, ya sea por desarrollar esa actividad sin autorización de una ley de quórum calificado o sin sujetarse a la legislación común aplicable en dicho ámbito a los particulares"32.

En el Considerando Décimo reitera el argumento de que el legislador de la ley $\mathrm{N}^{\circ} 18.971$ instituyó un mecanismo de tutela jurisdiccional específico para resguardar a los particulares frente al Estado empresario, y agrega "determinación que, de seguro, obedeció al convencimiento de quienes propiciaron el establecimiento de dicho cuerpo normativo en orden a que el recurso de protección contemplado en el artículo 20 de la misma Carta carecía de la aptitud requerida para constituir un

\footnotetext{
31. Considerando Séptimo.

32. Considerando Octavo.
} 
resguardo con la eficacia suficiente respecto de la intangibilidad que debe ostentar dicha garantía esencial"33.

La Corte esgrime un segundo argumento de hermenéutica civil, la interpretación sistémica de la ley $\mathrm{N}^{\circ} 18.971$ y el artículo 20 de la Constitución. El RAE se instituye como acción popular, "que trasunta el designio del legislador en orden a amparar por su intermedio el derecho a la libertad económica no en cuanto a transgresiones a la misma que afecten en general a los individuos particulares en su interés personal, sino cuando tales vulneraciones provengan de la actividad empresarial del Estado quebrantando las normas de Orden Público Económico consagradas en el tantas veces mencionado artículo $19 N^{\circ} 21$ inciso $2^{\circ}$ de la Constitución Política..." ${ }^{34}$. En cuanto a la necesidad de establecer este instrumento específico, y en relación con el recurso de protección, se destaca la insuficiencia de este último para asumir ese rol, debido, entre otras razones, a la falta de motivación de las personas individualmente consideradas para deducir un recurso de amparo económico, al no ser afectadas en un derecho subjetivo que les concierna en particular.

Siguiendo con la interpretación sistémica de ambos recursos, afirma que existen "fundadas razones" para estimar que el RAE no es un instrumento idóneo para proteger el derecho consagrado en el inciso primero del numeral 21. Y en este punto destaca: "la imposibilidad de estimar como criterio racional que una persona directamente afectada por la vulneración de dicha garantía constitucional disponga — conforme a lo establecido en el Auto Acordado de esta Corte que regula su tramitación y fallo - de treinta días para deducir el recurso de protección, en tanto que un tercero sin interés actual alguno en la materia, según lo prescribe la Ley $N^{\circ}$ 18.971, cuente para ello con un plazo de seis meses" ${ }^{\prime 3}$. Para Nogueira esta no es una razón fundada jurídicamente, sino un argumento de mérito, y el juez no tiene competencia para pronunciarse sobre el mérito de la decisión legislativa ${ }^{36}$.

33. Considerando Décimo.

34. Considerando Decimoprimero.

35. Considerando Decimosegundo.

36. NOGUEIRA, Humberto, ob. cit.

Facultad de Derecho y Ciencias Sociales - Universidad de Valparaíso - Chile 
En este análisis sistémico, y como segundo argumento, la Corte Suprema alude a la naturaleza cautelar del recurso de protección frente al carácter declarativo del recurso de amparo económico, materia que no abordaremos.

El contenido de esta sentencia ha sido reproducido desde entonces, al menos parcialmente, en resoluciones posteriores sobre la materia de la Sala Constitucional de la Corte Suprema.

\section{4.}

Con posterioridad al año 2012, la Corte Suprema ha dictado algunos fallos volviendo a la aplicación amplia del RAE, aun cuando no se trata de una jurisprudencia consistente que nos permita afirmar que ha existido un nuevo giro jurisprudencial en la materia.

Como nos señala Ponce de León el año 2013 "en la causa Rol $N^{\circ}$ 1944-2013, en la que se cuestionaba una actuación del Servicio de Impuestos Internos, la Tercera Sala de la Excma. Corte Suprema, en sentencia de 27 de mayo, señaló que no corresponde a ese Tribunal introducir restricciones que el legislador no ha establecido para la interposición de esta acción (Considerando Sexto) y que, por consiguiente, el Recurso de Amparo Económico puede ser intentado por cualquier persona y procedería, a su vez, por infracciones referidas a ambos incisos del numeral 21 del artículo 19 constitucional. Esa interpretación, añade la misma sentencia en comento, sería congruente con el principio pro homine y con jurisprudencia previa emitida por ese Máximo Tribunal de justicia en determinados casos, y bajo las mismas consideraciones actuales" ${ }^{\prime 37}$.

Sin embargo, en los meses de enero y marzo de 2014, la Corte Suprema ha vuelto a razonar en orden a que esta acción especial ha sido establecida para resguardar sólo la garantía reconocida en el inciso segundo del artículo $19 \mathrm{~N}^{\circ} 21$ de la Carta Fundamental.

Con fecha 5 de octubre de 2016, la Sala Constitucional de la Corte Suprema dictó sentencia en causa Rol No 47.914-2016 por

37. PONCE DE LEÓN, Sandra: "La Acción de Amparo Económico". En: María Pía Silva y Miriam Henríquez, coordinadoras: Acciones Protectoras de Derechos Fundamentales. Legalpublishing, Santiago, 2014. Pp. 97-126. 
apelación de acción de amparo económico prevista en la ley $\mathrm{N}^{\circ} 18.971$ ante una infracción a la garantía de desarrollar cualquier actividad económica lícita garantizada en el artículo 19 No21 inciso primero de la Constitución Política de la República, acogiendo el recurso interpuesto por un pescador artesanal, quien denunció que se habría vulnerado su derecho a desarrollar cualquier actividad económica al cerrarse el acceso a la playa por un particular, impidiendo de esta forma que pudiera ingresar a realizar la actividad de pesca artesanal, sentencia en que la Corte Suprema hace referencia a la aplicabilidad del recurso de amparo económico, señalando que sería procedente no solo para aquellos casos en que existe vulneración por la actividad empresarial del Estado, sino que también a la garantía del libre desarrollo de cualquier actividad económica que no sea contraria a la moral, al orden público o a la seguridad nacional. En este sentido, en su considerando sexto, indica: "Que es evidente que el legislador, al regular el amparo económico en el artículo único de la ley $N^{o}$ 18.971, no hizo distingo alguno en cuanto al ámbito de su aplicación. Esta garantía constitucional — a la que se le ha llamado de libre iniciativa o de libertad de empresa-es de contenido vasto, puesto que comprende la libre iniciativa y la prosecución indefinida de cualquier actividad económica, sea productiva, comercial, de intercambio o de servicio, habiendo sido introducida por el Constituyente de 1980 con especial énfasis y estudio, según consta de la historia fidedigna del precepto".

El considerando octavo agrega que "se añade el antecedente pacífico que la Ley $N^{\circ} 18.971$ no establece restricciones, esta surge solamente de una interpretación, actividad que en el orden de las garantías constitucionales debe ejercerse en favor de las personas, nunca se debe a través de ella restringirle los derechos, puesto que contraría el sentido último de las declaraciones de derechos en los textos constitucionales y legales. En el mismo sentido se encuadra la interpretación pro homine o a favor de las personas".

Finalmente, la sentencia señala en su considerando noveno los motivos por lo que no debe considerarse el recurso de amparo económico de forma restringida para la protección del artículo $19 \mathrm{~N}^{\circ} 21$ inciso 2: "Que el menoscabo que pueda sufrir la garantía constitucional contenida en el artículo $19 N^{\circ} 21$ en el ejercicio de cualquier actividad económica, no está sujeta a limitación alguna, por lo que no puede hacerse distingo sobre sus titulares. De esta manera, no se advierte razón por la cual fuese razonable

Facultad de Derecho y Ciencias Sociales - Universidad de Valparaíso - Chile 
utilizar, incluso, reglas de hermenéutica legal para introducir una restricción que el legislador no ha querido. En efecto, su intención aparece dirigida a otorgar una protección más bien general, sin discriminación alguna"38.

\section{Delimitación conceptual de las acciones en estudio}

\subsection{La acción de protección protege el derecho establecido en el inciso primero del numeral 21, artículo 19 de nuestra Constitución}

La interpretación constitucional obliga a buscar el sentido útil de cada una de las disposiciones del texto supremo, la máxima eficacia a los enunciados normativos constitucionales. El artículo 20 de la Constitución Política de la República consagra el recurso o acción de protección, acción cautelar que se dirige a proteger "derechos o garantías" establecidos en las disposiciones que enumera. De acuerdo a lo expuesto en el presente artículo respecto del contenido normativo del numeral 21, sólo el inciso primero contiene un derecho de aquellos que la Constitución consagra como "fundamentales", y por tanto sólo este inciso es cautelado por el recurso de protección.

La acción de protección es la que hace más eficaz el derecho contenido en esta disposición, pues el Tribunal competente, esto es, la Corte de Apelaciones respectiva, está expresamente autorizada para adoptar todas las medidas necesarias para restablecer el imperio del derecho y asegurar la debida protección del afectado.

\subsection{La acción de amparo económico vela por el cumplimiento de los} requisitos para el desarrollo de actividades empresariales por parte del Estado, establecidos en el inciso segundo del numeral $21 \mathrm{del}$ artículo 19 de la Constitución Política del Estado

En mi parecer, la Corte Suprema consagró en la tercera etapa una interpretación que, como exige el Tribunal Constitucional, se aviene mejor con el respeto de los derechos constitucionales ${ }^{39}$.

38. ZÚÑIGA, Francisco: Resurrección del Recurso de Amparo Económico. En: El Mercurio Legal, 28 de noviembre de 2016.

39. Tribunal Constitucional, Rol 1361-09.

Revista de Ciencias Sociales - Número 71 (2017) - Universidad de Valparáíso - ISSN 0716-7725-Valparaíso, Chile 
El razonamiento en que fundo esa afirmación es el siguiente:

1. La ley $\mathrm{N}^{\circ} 18.971$, dictada el año 1990 , se enmarca dentro de las disposiciones tendientes a complementar el texto constitucional. Transcurrido un tiempo ya desde la vigencia de la Carta de 1980, es sin duda perceptible para los legisladores que el principio de subsidiariedad en materia económica y el actuar del Estado empresario no estaban suficientemente resguardados. No obstante la acción de protección no distinguiera entre ambos incisos del numeral 21, el análisis propio de dicho recurso lleva a determinar que se trata de un instrumento inidóneo para salvaguardar los requisitos tanto de forma como de fondo (en caso de sostener la existencia de requisitos de fondo) que rigen el actual del Estado empresario. En particular, la exigencia que la acción de protección se ejerza por el titular de un derecho fundamental conculcado, lo hace en la práctica de difícil procedencia tratándose del inciso segundo del numeral 21, que mira al interés público más que a un interés particular. Ello explica la intención de la denominada "Comisión Fernández" de dictar una ley que regulara el actuar del Estado empresario, proyecto del que sabemos sólo prosperaron dos artículos, desgajados en cuerpos legales diferentes. Es así como el artículo único de la ley $\mathrm{N}^{\circ} 18.971$ consagró el RAE.

2. Uno de los argumentos más esgrimidos para afirmar que el RAE protege ambos incisos del ya tantas veces citado numeral 21, es un argumento de texto. En relación a este argumento, coincido con la Corte Suprema en el fallo "González Illanes con I. Municipalidad de Santiago", cuando afirma que el tenor literal es claro, pero no lo es su sentido. Precisamente por la oscuridad del sentido de la ley tenemos el panorama jurisprudencial y doctrinal relativo al artículo único de la ley $\mathrm{N}^{\circ} 18.971$ reseñado. El propio Nogueira ${ }^{40}$ reconoce que desde la entrada en vigencia del RAE se discutió si procedía para denunciar las infracciones cometidas respecto de cualquiera de los dos incisos del artículo $19 \mathrm{~N}^{\circ} 21$ de la CPR, o si era procedente sólo para denunciar infracciones al inciso segundo de dicha norma.

40. NOGUEIRA, Humberto, ob. cit.

Facultad de Derecho y Ciencias Sociales - Universidad de Valparaíso - Chile 
Por tanto, en mi parecer, el intérprete (v.gr., el juez) tiene abierta la puerta para recurrir a otros criterios de interpretación, como el de la historia fidedigna de su establecimiento o el sistemático. Pero esta forma de interpretación corresponde al ámbito del derecho civil, y en este punto coincido con Nogueira: una ley que complementa la Constitución debe interpretarse a la luz de criterios de interpretación constitucional. La interpretación de la Constitución busca determinar el sentido y alcance de las disposiciones constitucionales, para lo cual se vale de una serie de reglas que sobrepasan las clásicas propuestas por Savigny, pensadas para un sistema de reglas y no de principios.

Nogueira afirma que la interpretación del juez debe dirigirse hacia aquellas alternativas que "optimicen o maximicen la eficacia de las normas constitucionales, sin distorsionar su contenido, y que los tribunales superiores de justicia cuando actúan como jueces constitucionales deben aplicar el principio 'favor persona' o 'pro homine"”41.

Coincido con su afirmación pero discrepo en relación a las consecuencias que ella tiene. Interpretar el artículo único de la ley $\mathrm{N}^{\circ}$ 18.971, en relación con las Bases de la Institucionalidad, el artículo $19 \mathrm{~N}^{\circ} 21$ y el artículo 20, y siempre a favor de la persona y tendiendo a maximizar la eficacia de la Constitución, no se traduce en mi parecer en establecer que la garantía de la libertad económica, establecida en el inciso primero, deba protegerse por ambas acciones, la de amparo económico y la de protección. Por el contrario, delimitar ambas acciones las dota de especificidad, y permite, en consecuencia, una mejor protección de sus respectivos objetos. La libertad económica está debidamente resguardada, pero al hacer el RAE extensivo a ambos incisos, se desnaturaliza y pierde su objetivo, velar porque el Estado y sus organismos respeten el Estatuto que la Constitución ha establecido para permitir su intervención en actividades empresariales.

3. Tanto Nogueira como Hernández esgrimen como uno de los principales argumentos para afirmar que el RAE tiene un alcance amplio, la obligación del Estado de Chile de cumplir con los deberes que ha asumido como signante de tratados internacionales, por ejemplo, la Convención Americana. Resulta poco preciso afirmar que incum-

41. Ídem.

Revista de Ciencias Sociales - Número 71 (2017) - Universidad de Valparáíso - ISSN 0716-7725-Valparaíso, Chile 
pliríamos normas tales como el artículo $1^{\circ}$ de la Convención Americana de Derechos Humanos, que establece la obligatoriedad a los Estados partes de dotar de efectividad a los derechos, o el citado artículo 25, puesto que nuestro ordenamiento constitucional contempla recursos efectivos, el más efectivo de ellos, el recurso de protección, establecido precisamente para salvaguardar el inciso primero del numeral 21 ya citado.

4. La interpretación del artículo único de la ley $\mathrm{N}^{\circ} 18.971$, debe hacerse a la luz de los criterios de interpretación constitucional, por ser una norma complementaria de la Carta Fundamental. No deben ser desechados los criterios tradicionales de interpretación, heredados del derecho civil, pero ellos no son suficientes. En relación a la "literalidad", el propio Tribunal Constitucional ha señalado que "una interpretación literal o basada en el principio de la especialidad o en el aforismo jurídico de que donde la ley no distingue no le es lícito al intérprete hacerlo, establecidas o reconocidas por el Código Civil, para la interpretación de las leyes, no reciben aplicación en el presente caso, atendida la naturaleza especial del problema que se analiza y del texto que se interpreta..."

5. El aforismo 'donde la norma no distingue no es lícito al intérprete distinguir' no se aplica en este caso porque una interpretación sistemática (especialmente considerando lo no publicado de aquel proyecto de ley), permite sostener que el tenor literal sólo omite algo que se hace evidente al examinar las características de los incisos $1^{\circ}$ y $2^{\circ}$ y de las acciones en cuestión.

La interpretación del artículo único de la ley $\mathrm{N}^{\circ} 18.971$ está en directa relación con uno de los principios estructuradores de nuestra Constitución, contenidos, fundamental pero no únicamente, en el Capítulo I "Bases de la Institucionalidad". En efecto, el artículo 19 $\mathrm{N}^{\circ} 21$ forma parte del Capítulo III, "Derechos y Deberes Constitucionales", pero por una interpretación doctrinaria, basada en el informe $\mathrm{N}^{\circ}$ 6.583/160/1, de 12 de junio de 1989, la Comisión Conjunta que informó la ley de reforma constitucional $\mathrm{N}^{\circ} 18.825$, de fecha 17 de agosto de 1989, se entiende que son parte de las "Bases de la Institucionalidad"

42. Rol 325 del Tribunal Constitucional, de 26 de junio de 2001, considerando $13^{\circ}$.

Facultad de Derecho y Ciencias Sociales - Universidad de Valparaíso - Chile 
sobre las cuales se funda la CPE de 1980, no solo las indicadas en el Capítulo I, sino también las del Capítulo III, ya que ambos Capítulos conforman la dogmática de la Constitución, por lo que el 19 Nº 21 es una base de la institucionalidad, es decir es parte de los principios, ideas, valores e inspiraciones fundamentales que orientan el proceso de creación y transformación del derecho constitucional chileno" ${ }^{43}$.

6. El problema del ámbito de aplicación del amparo económico debemos analizarlo en relación a la interpretación que se ha dado a los bienes jurídicos protegidos. La acción de amparo económico no protege, en mi opinión, el inciso primero del numeral 21 del artículo 19 de la Constitución, no se trata de una acción cautelar de un derecho fundamental.

El RAE cautela el Estatuto del Estado empresario, y el cumplimiento por parte del Estado y sus organismos de la normativa constitucional que prescribe los requisitos para su intervención en actividades empresariales, cuestión que interesa no solo a una persona determinada, sino que a la comunidad toda. Ello se reafirma considerando no sólo la historia de su establecimiento ${ }^{44}$, sino caracteres de la acción que revelan este carácter.

a) Se trata de una acción popular. Conceptualmente, la acción popular dice relación con el ejercicio del derecho de la acción por sujetos, sin que se exija tener algún grado de vinculación de su pretensión con la relación jurídico-material que se deduce en el proceso ${ }^{45}$.

43. URETA, Ismael: Recurso de Amparo Económico. Segunda Edición actualizada por Ricardo Riesco Eyzaguirre, Editorial Lexis Nexis, Santiago, 2002.

44. El Mensaje con que se dio inicio a la tramitación de la ley $\mathrm{N}^{\circ} 18.971$ nos puede orientar respecto a su ámbito de aplicación. Destaca el $19 \mathrm{~N}^{\circ} 21$ como una norma que incentiva la iniciativa privada y evita el mal que significa la proliferación de empresas del estado. Indica expresamente que la iniciativa tiene por finalidad determinar cuál es la dimensión adecuada para el Estado Productor. En Hue Christian: Las facultades conservadoras de los Tribunales de Justicia y en especial el Recurso de Amparo Económico. - Memoria de prueba para optar al grado de Licenciado en Ciencias Jurídicas y Sociales. Facultad de Derecho de la Universidad Finis Terrae, 1995.

45. ROMERO, Alejandro: Curso de Derecho Procesal Civil. La acción y la protección de los derechos. Tomo I, Editorial Jurídica de Chile, Santiago, 2007.

Revista de Ciencias Sociales - Número 71 (2017) - Universidad de Valparáiso - ISSN 0716-7725-Valparaíso, Chile 
Tratándose del inciso segundo, en relación con las normas contenidas en las Bases de la Institucionalidad, efectivamente hay un interés público comprometido, y no hay, al menos necesariamente, un individuo afectado, sino que lo es el orden público económico, o simplemente la norma que establece cómo se manifiesta el Estado empresario. Ello se condice perfectamente con el carácter de norma complementaria de principio que tiene la ley $\mathrm{N}^{\circ} 18.971$, velando porque sea realizado en la mayor medida posible. Se resguarda no sólo el inciso segundo, sino un conjunto de disposiciones que lo complementan: artículo $1^{\circ}$, particularmente sus incisos 3 y 4 , que consagran la subsidiaridad; artículo $5^{\circ}$, que limita el poder estatal; los artículos $6^{\circ}$ y $7^{\circ}$, que establecen que el ejercicio del poder, la actuación de quienes lo detentan, debe someterse a la Constitución y a las normas dictadas conforme a ella, entre otras.

b) Se trata de una acción declarativa, el Tribunal no está facultado para adoptar medidas de emergencia. El proyecto de ley que dio origen a la ley $\mathrm{N}^{\circ} 18.971$ sí lo contemplaba, pero la disposición no prosperó. En mi entender, existe una razón para ello: el RAE no se estableció para proteger a los particulares frente al Estado o la Administración, en situaciones que pudiesen subsanarse adoptando "medidas necesarias para restablecer el imperio del derecho". El fundamento del RAE es lejano a ello. La Corte de Apelaciones respectiva, en primer término, y la Corte Suprema en su caso, deberán analizar, ante el requerimiento de cualquier persona, si el Estado o sus organismos, extralimitándose del ámbito de su competencia, desarrollan actividades económicas sin cumplir con los requisitos que contempla el Estatuto del Estado empresario.

c) Se contempla el trámite de la consulta.

7. Concluimos así, que la interpretación constitucionalmente útil, finalista y armónica de una norma complementaria de la Constitución no es otra que el RAE es sólo procedente ante infracciones al inciso segundo del numeral 21, artículo 19, de la Constitución Política de la República. Los fundamentos de esta interpretación son los que he expuesto precedentemente.

Facultad de Derecho y Ciencias Sociales - Universidad de Valparaíso - Chile 


\section{Conclusiones}

1. El artículo $19 \mathrm{~N}^{\circ} 21$ de la Constitución Política de la República contempla dos disposiciones de contenido normativo diverso: mientras el inciso $1^{\circ}$ establece un derecho fundamental, el inciso $2^{\circ}$ consagra el Estatuto del Estado empresario.

El inciso primero de la disposición consagra un derecho público subjetivo que el constituyente consagra como derecho fundamental, el derecho a la libertad económica. A su vez, el inciso segundo establece el Estatuto del Estado empresario, requisitos formales para que el Estado y sus organismos actúen en el ámbito empresarial. La ubicación de esta norma en el artículo 19 responde, en mi visión, no a su carácter de derecho fundamental, sino a la intención de establecer las reglas que el Estado debe respetar para desarrollar actividades económicas.

Aun cuando se suele afirmar que esta norma es la base del orden público económico, por cuanto establece una economía social de mercado a partir del principio de subsidiaridad, me parece más adecuado, superando los criterios originalistas de interpretación constitucional, constatar que se trata de disposiciones que consagran un orden jurídico económico, un "mínimum constitucional" de carácter abierto y dinámico.

La Constitución es unitaria, y desde esa perspectiva, ambos incisos del artículo $19 \mathrm{~N}^{\circ} 21$ deben interpretarse armónicamente con los principios que establece la Constitución, principalmente en el Capítulo I sobre Bases de la Institucionalidad, entre los que se cuentan el principio de subsidiariedad, el de igualdad y el de solidaridad.

2. El recurso de amparo económico está establecido para tutelar el art. $19 \mathrm{~N}^{\circ} 21$ inc. $2^{\circ}$ de la Constitución. El artículo único de la ley $\mathrm{N}^{\circ} 18.971$ prescribe un recurso especial para denunciar las infracciones al numeral 21 del artículo 19 de la Constitución Política de la República, sin restringir el ámbito de tutela al inciso segundo de la norma.

No obstante y como fruto del presente trabajo, me permito afirmar que su finalidad es cautelar sólo el inciso segundo de la referida disposición. Sostengo que si bien es conveniente modificar la norma y evitar constantes cambios jurisprudenciales que afecten la certeza jurídica en la aplicación de las acciones constitucionales en cuestión, la 
interpretación del RAE hecha por la Corte Suprema el año 2009, de carácter restrictiva y específica, emana de la interpretación unitaria, sistemática y pro homine de los artículos $19 \mathrm{~N}^{\circ} 21$ y 20 de la Constitución, y el artículo único de la ley $\mathrm{N}^{\circ} 18.971$.

La acción de protección cautela el ejercicio de los derechos fundamentales y, según hemos visto, sólo el artículo $19 \mathrm{~N}^{\circ} 21$ inciso $1^{\circ}$ consagra un derecho, el derecho a la libertad económica. El particular que se vea lesionado en su derecho ejercerá la acción jurisdiccional que le concede el artículo 20, una acción jurisdiccional rápida y efectiva, tal como lo exigen las convenciones internacionales que Chile ha suscrito.

Por su parte, el recurso de amparo económico es, como señala el epígrafe de la ley, un recurso especial. El proyecto de ley original regulaba la actividad y participación productiva del Estado y sus organismos y establecía, en su artículo $6^{\circ}$, esta acción jurisdiccional para garantizar el cumplimiento de dicho estatuto. Sin embargo, el proyecto de ley nunca vio la luz y sólo fue promulgada la norma que contemplaba la acción en comento, la ley $\mathrm{N}^{\circ} 18.971$. No se trata de un recurso que cautele derechos fundamentales, tanto por la estructura normativa de las disposiciones en cuestión como por la interpretación sistemática de ellas.

En efecto, se trata de una acción diseñada para cautelar un interés público comprometido, el que sólo se ve presente en el art. $19 \mathrm{~N}^{\circ} 21$ inciso $2^{\circ}$ y no en el inciso $1^{\circ}$ (que, incluso, se protege con una acción privada). Tanto el carácter de acción pública como el trámite de la consulta y hasta su extendido plazo, dan cuenta de la intención de proteger un interés que desborda los requerimientos particulares del ejercicio de un derecho fundamental. Asimismo, el alcance que le otorga al RAE la jurisprudencia desde el año 2009 se aviene con la finalidad del recurso, la historia de su establecimiento y su interpretación sistemática con el artículo $19 \mathrm{~N}^{\circ} 21$ y artículo 20, ambos de la Constitución.

3. Atendido que el criterio de la Corte Suprema ha experimentado importantes variaciones desde el año 1990, la inestabilidad de la jurisprudencia sobre la materia aconseja modificar la normativa vigente.

$\mathrm{Al}$ respecto propongo:

Facultad de Derecho y Ciencias Sociales - Universidad de Valparaíso - Chile 
a. Elevar a rango constitucional la acción de amparo económico.

b. Señalar expresamente que sólo procede infracciones al estatuto del Estado empresario.

c. Contemplar en la normativa propia del RAE normas mínimas de procedimiento.

d. Regular la adopción de medidas de emergencia por parte del tribunal competente.

\section{BIBLIOGRAFÍA}

ALDUNATE LIZANA, Eduardo: "Categorías para el análisis de la argumentación jurídica del Tribunal Constitucional. Los argumentos sobre la base del tenor literal y la interpretación armónica”. En: Revista Chilena de Derecho, 1998. Pp. 115-120.

ARÓSTICA MALDONADO, Iván: "Derecho Administrativo Económico. Libre iniciativa privada y actividad empresarial del Estado", Primera Edición, Santiago de Chile, Escuela de Derecho, Universidad Santo Tomás, 2001.

ARÓSTICA MALDONADO, Iván: "Acción de Amparo Económico. Acerca del recurrente y el recurrido". En: Gaceta jurídica, $\mathrm{N}^{\circ}$ 182, ago. 1995. Pp. 7-14.

ARÓSTICA MALDONADO, Iván: "Crónica sobre la expansión del Estado Empresario y el retraimiento de la iniciativa privada”. En: Ius Publicum, Universidad Santo Tomás, Escuela de Derecho, vol. 2, N 2, mar. 1999. Pp. 129-146.

AVILÉS HERNÁNDEZ, Víctor Manuel: “Orden Público Económico: Noción crítica”. En: Revista de Derecho Público, vol. 63, 2001. Pp. 329-338.

BASSA MERCADO, Jaime: "Los criterios de interpretación constitucional en el Estado contemporáneo”. En: Carvajal, Patricio y Miglietta, Massimo, Estudios jurídicos en homenaje al profesor Alejandro Guzmán Brito, Edizioni Dell'Orso, Milán, 2011. Pp. 301-322.

BASSA MERCADO, Jaime: "El Estado constitucional de Derecho y la interpretación flexible de la Constitución”. En: Revista de Derecho Público, Universidad de Chile, vol. 69, 2007. Pp. 104-121.

Revista de Ciencias Sociales - Número 71 (2017) - Universidad de Valparáíso - ISSN 0716-7725-Valparaíso, Chile 
BASSA MERCADO, Jaime y VIERA ÁLVAREZ, Christian: "Contradicciones de los fundamentos teóricos de la Constitución chilena con el Estado constitucional: notas para su reinterpretación”. En: Revista de Derecho, Universidad Austral de Chile, vol. XXI n², 2008. Pp. 131150.

BERNAL PULIDO, Carlos: "Estructura y límites de la ponderación". En: Doxa, N 26, 2003. Pp. 225-238.

BERTELSEN REPETTO, Raúl: "El Estado empresario en la Constitución de 1980". En: Revista Chilena de Derecho, vol. 14, 1987. Pp. 115-125.

CEA EGANAA, José Luis: Tratado de la Constitución de 1980. Características Generales Garantías Constitucionales. Primera edición, Editorial Jurídica de Chile, Santiago, 1998.

CEA EGAÑA, José Luis, "Notas sobre Orden Público Económico”, Gaceta jurídica. (Santiago, Chile). No 135 (sep.1991), pp. 18-32.

CEA EGAÑA José Luis: "Fisonomía histórica y prospectiva de la Constitución de 1980". En: Revista de Derecho, Universidad Austral de Chile, vol. VI, dic.1995. Pp. 7-27.

COVARRUBIAS CUEVAS, Ignacio: "Subsidiariedad y Estado Empresario (Análisis Crítico de la Jurisprudencia más relevante)". En:

Revista de Derecho Público, vol. 66, 2004. Pp. 251 y sgtes.

CUEVAS FARREN, Gustavo: "Protección constitucional de la libertad económica. Notas y reflexiones”. En: Letras jurídicas, Revista electrónica de Derecho, Universidad de Guadalajara, N² 2, 2006.

DÍAZ SANHUEZA, Francisco: Protección Constitucional de la libertad económica. Memoria para optar al grado académico de Licenciado en Ciencias Jurídicas y Sociales. Universidad de Talca, Facultad de Ciencias Jurídicas y Sociales, Escuela de Derecho, 2003.

DOUGNAC RODRÍGUEZ, Fernando: "La garantía constitucional del $N^{\circ} 21$ del artículo 19 de la Constitución en relación con los demás que configuran el "orden público económico". En: Gaceta Jurídica, No 68, 1986. Pp. 6-12.

ESTÉVEZ VALENCIA, Jaime: "Visión sobre la Constitución Económica”. En: Revista de Derecho Público, vol. 62, 2000. Pp. 97-103.

Facultad de Derecho y Ciencias Sociales - Universidad de Valparaíso - Chile 
EVANS DE LA CUADRA, Enrique: Los Derechos Constitucionales. Segunda edición Actualizada, Editorial Jurídica de Chile, Santiago, 1999.

FERMANDOIS VÖHRINGER, Arturo: "Ripert y su influencia en el concepto de orden público económico: auge y caída de una visión dirigista". En: Revista Chilena de Derecho, vol. 32, No 1, 2005. Pp. 7-18. FERMANDOIS VÖHRINGER, Arturo: Derecho Constitucional Económico: garantías económicas: doctrina y jurisprudencia. Segunda edición Actualizada, Ediciones Universidad Católica de Chile, Santiago, 2006.

GÓMEZ BERNALES, Gastón: "Temas actuales de Derecho Constitucional. Notas sobre el recurso de amparo económico. La Jurisprudencia y la Fisonomía de la acción. 2001-2006”. En: Asociación Chilena de Derecho Constitucional. Primera Edición, Editorial Jurídica de Chile, Santiago, 2009. Pp. 97 y sgtes.

GÓMEZ BERNALES, Gastón: Derechos fundamentales y Recurso de Protección. Ediciones Universidad Diego Portales, Santiago, 2005. GONZÁLEZ GRANDJEAN, Denis: La libertad económica y su protección jurídica en la Constitución chilena: un análisis a través de la jurisprudencia. Memoria para optar al Grado de Licenciado en Ciencias Jurídicas y Sociales, Facultad de Derecho, Universidad de Chile, Santiago. 2001.

GUERRERO BECAR, José Luis: Regulación Constitucional del Orden Económico. La Experiencia chilena: Constitución Política de la República de 1980. Memoria de prueba para optar al grado de Licenciado en Ciencias Jurídicas de la Universidad Católica de Valparaíso, 1991.

HERNÁNDEZ EMPARANZA, Domingo: "El recurso de Amparo Económico: una tendencia jurisprudencial peligrosamente reduccionista”. En: Estudios Constitucionales, año 8, N 1, 2010. Pp. 443-466.

HUE WHELANDT, Christian: Las facultades conservadoras de los Tribunales de Justicia y en especial el Recurso de Amparo Económico. Memoria de prueba para optar al grado de Licenciado en Ciencias Jurídicas y Sociales. Facultad de Derecho de la Universidad Finis Terrae, 1995.

Revista de Ciencias Sociales - Número 71 (2017) - Universidad de Valparáíso - ISSN 0716-7725-Valparaíso, Chile 
JAEDERLUND LÜTTECKE, John: El recurso de amparo económico. Doctrina, procedimiento y jurisprudencia. Librotecnia, Santiago, 1999.

LÓPEZ MAGNASCO, Sebastián: Garantía Constitucional a la no discriminación económica. Memoria de Prueba, Licenciatura en Ciencias Jurídicas y Sociales, Universidad Adolfo Ibáñez, 2003.

MORAGA FRITZ, Álvaro: La acción de amparo económico. Principios y Fundamentos que la sustentan. Memoria de pregrado, Facultad de Derecho, Universidad Adolfo Ibáñez, 1998.

MORESO, Juan José: "Algunas consideraciones sobre la interpretación constitucional" En: Doxa, N²3, 2000. Pp. 105 y sgtes.

MUÑOZ LEÓN, Fernando: "La interpretación originalista de nuestra constitución ¿es posible y deseable?”. En: Revista de Derecho Público, Universidad de Chile, No 69, 2007. Pp. 383-388.

NAVARRO BELTRÁN, Enrique: "Temas Actuales de Derecho Constitucional. 30 años del Recurso de Protección”. En: Asociación

Chilena de Derecho Constitucional: Temas Actuales de Derecho Constitucional. Libro Homenaje al Profesor Mario Verdugo Marinkovic. Editorial Jurídica de Chile, 2009. Pp. 141-154.

NAVARRO BELTRÁN Enrique, "La libertad económica y su protección”, Revista del Abogado $\mathrm{N}^{\circ} 24$ (abril 2002), pp. 28 y siguientes.

NOGUEIRA ALCALÁ, Humberto: "Análisis Crítico sobre la línea jurisprudencial de la Sala Constitucional de la Excma. Corte Suprema de Justicia sobre el Recurso de Amparo Económico". En: Ius et Praxis, vol. 16, $\mathrm{N}^{\circ}$ 2, 2010. Pp. 415-441.

NIÑO PARADA, Eduardo: La vigencia del principio de subsidiariedad en la actividad empresarial del Estado. Editorial Lexis Nexis, Santiago, 2006.

NOGUEIRA ALCALÁ, Humberto (Coordinador): La ciencia del derecho procesal constitucional. Estudios en homenaje a Héctor Fix-

Zamudio en sus cincuenta años como investigador del derecho. Librotecnia, Santiago, 2009.

PFEFFER URQUIAGA, Emilio: "El recurso de protección y su eficacia en la tutela de derechos constitucionales en Chile". En: Estudios Constitucionales, año $4 \mathrm{~N}^{\circ}$ 2. 2006. Pp. 87-107.

Facultad de Derecho y Ciencias Sociales - Universidad de Valparaíso - Chile 
PINTO CEBALLOS, Jorge: "El recurso de amparo económico y su ámbito de protección: una polémica no resuelta". En: Revista de

Derecho y Humanidades, $\mathrm{N}^{\circ}$ 11, 2005. Pp. 267-278.

RAZ, Joseph: "La intención en la interpretación”. En: Doxa, $\mathrm{N}^{\circ} 20$, 1997. Pp. 199-233.

RÍOS ÁLVAREZ, Lautaro: "La acción constitucional de protección en el ordenamiento jurídico chileno". En: Revista de Ciencias

Sociales, Universidad de Valparaíso, Facultad de Derecho y Ciencias Sociales, No 53, 2008. Pp. 153-186.

ROMERO SEGUEL, Alejandro: Curso de Derecho Procesal Civil. La acción y la protección de los derechos. Tomo I. Editorial Jurídica de Chile, Santiago, 2007.

RUIZ-TAGLE VIAL, Pablo: "Principios Constitucionales del Estado Empresario". En: Revista de Derecho Público, vol. 62, 2000.

Pp. 48-65.

SQUELLA NARDUCCI, Agustín: Introducción al Derecho. Segunda edición actualizada y ampliada. Editorial Jurídica, Santiago.

URETA SILVA, Ismael: Recurso de Amparo Económico. Segunda Edición actualizada por Ricardo Riesco Eyzaguirre. Editorial Lexis

Nexis, Santiago, 2002.

TAPIA VALDÉS, Jorge: "La neosubsidiariedad: el principio de subsidiariedad en el proyecto de constitución europea”. En: Corpus Iuris

Regionis. Revista Jurídica Regional y Subregional Andina, Iquique, $\mathrm{N}^{\circ}$ 6, 2006. Pp. 379-397.

ZAVALA ORTIZ, José Luis: "Amparo Económico: ¿Una acción desvirtuada?”. En: Gaceta Jurídica, N 249, año 2001.

ZÚÑIGA URBINA, Francisco: "Constitución económica y Estado empresario": En: Revista de Derecho Público, № 63, Tomo I, año

2001. Pp. 339 y sgtes.

ZÚNIGA URBINA, Francisco: "El Recurso de Amparo Económico Revistado. Post Scriptum”. En: Gaceta Jurídica, N²66. Pp. 7-12.

ZÚNIIGA URBINA, Francisco: "Constitución y amparo económico". En: Gaceta jurídica, No 145, jul. 1992. Pp. 10-18.

ZÚNIGA URBINA, Francisco: "Resurrección del Recurso de Amparo Económico”. En: El Mercurio Legal, 28 de noviembre de 2016.

Revista de Ciencias Sociales - Número 71 (2017) - Universidad de Valparaíso - ISSN 0716-7725-Valparaíso, Chile 